\title{
Covid-19 y la suspensión de la relación laboral por contingencia sanitaria en México
}

\author{
José MANuel OSORIO ATONDO1*
}

\section{RESUMEN}

La pandemia ocasionada por la propagación de la covid-19 ha simbolizado el desafío más trascendental que ha enfrentado la sociedad mexicana, en virtud de que tal suceso ha incidido gravemente en la salud y en la economía, poniendo a prueba a las instituciones políticas y sociales en su combate. Pero, además, tal crisis ha puesto en evidencia también la debilidad de nuestro marco jurídico laboral, al manifestarse una controversia en la aplicación y ejecución de la Ley Federal del Trabajo en correlación con la suspensión de la relación laboral por contingencia sanitaria y lo manifestado por el Consejo de Salubridad General al optar por utilizar el término de emergencia sanitaria en su declaratoria.

Palabras clave: covid-19, suspensión laboral, contingencia sanitaria, emergencia sanitaria.

\section{COVID-19 HEALTH CONTINGENCY AND THE SUSPENSION OF THE EMPLOYER-EMPLOYEE RELATIONSHIP IN MEXICO}

\section{ABSTRACT}

The pandemic caused by the spread of covid-19 constitutes one of the most serious challenges ever faced by Mexican society. It has exerted severe impacts on health and the economy, while putting both political and social institutions, which have struggled to respond, to the test. Additionally, this health crisis has highlighted the inadequacy of the legal framework governing labor relations in Mexico. This situation

1 Profesor investigador de tiempo completo de la Universidad Estatal de Sonora (UES). ORCID: 0000 0001-8508-9953.Correo electrónico: jose.osorio@ues.mx

* DOI: https://doi.org/10.18601/01236458.n55.14 
has come to the fore in the recent controversy surrounding enforcement and execution of the Federal Labor Act for cases of suspension of employment under the public health contingency and the General Board of Health's choice of words, i.e., 'health emergency', in a recent declaration.

Keywords: covid-19, suspension of employment, health contingency, health emergency.

\section{INTRODUCCIÓN}

La crisis sanitaria por la pandemia provocada por la covid-19 ha incidido en la salud, en la economía, en el empleo y en el bienestar de los mexicanos; contexto en el cual el Gobierno federal emitió una serie de acciones y medidas para mitigar dicha enfermedad y evitar o disminuir en lo posible los decesos ocasionados por esta. En tales estrategias destacan la campaña denominada Susana Distancia, la declaración de "emergencia sanitaria" y la suspensión de actividades no esenciales del sector público, privado y social.

Sin embargo, el coronavirus ha evidenciado la debilidad en nuestro sistema de salud al no estar preparados para un problema de tal magnitud, requiriéndose de espacios especiales, respiradores, medicamentos, entre otros equipos y suministros indispensables. Además, tal experiencia nos ha demostrado la falta de pertinencia en el marco jurídico, específicamente en el ejercicio y aplicación de la norma jurídica laboral en correspondencia a la legislación en materia de salud.

De tal manera que en el presente artículo se exhibe la discrepancia jurídica en la adaptación y ejecución de la suspensión laboral por "contingencia sanitaria" con fundamento en la Ley Federal del Trabajo (LFT) y en relación con la declaratoria emitida por el Consejo de Salubridad General al emplear la expresión de "emergencia sanitaria", requiriéndose de manera apremiante una reforma en búsqueda de la congruencia en la legislación laboral y en materia de salud para el caso concreto en México.

\section{EL ESCENARIO DE LA PANDEMIA EN MÉXICO}

En los últimos meses, el escenario mundial exhibe sin precedente una de las peores crisis sanitaria, humana y económica que se despliega interminablemente ocasionada por la pandemia del coronavirus (covid-19), la cual ha provocado el cierre de fronteras, sociedades en aislamientos y economías paralizadas, todo ello con una gran incidencia negativa a corto, mediano y largo plazo, tales como el incremento en el desempleo, menores ingresos salariales, incremento de la pobreza, quiebras de empresas, disminución de la inversión privada, menor integración de las cadenas de valor, mínimo crecimiento económico y, por ende, el deterioro de las capacidades productivas y de capital humano (CEPAL, 2020). Sin soslayar las cifras de más de veintiséis millones de contagios y por encima de los 860 mil decesos en el mundo al inicio del mes de 
septiembre del 2020, según los datos emitidos en tiempo real por la Johns Hopkins School y expuestos por el Instituto Mexicano del Seguro Social (IMSS), siendo, además, la región de las Américas la que reporta el mayor número de dichas defunciones de tal enfermedad en el mundo según la Organización Panamericana de la Salud (OPS) a la misma fecha.

Para el caso que nos ocupa, México ha sido uno de los países mayormente afectados por la epidemia en mención, de tal forma que, según datos proporcionados por el gobierno, al inicio del mes de septiembre del 2020 exhibió más de 610 mil casos confirmados y por encima de 65 mil defunciones lamentables (covid-19 Tablero México), posicionando al país entre las diez naciones con más contagios de dicha enfermedad y por si fuera poco en el primer lugar en defunciones de personal de la salud, por encima de Estados Unidos, Reino Unido, Brasil, Rusia, India, Sudáfrica, Italia, Perú, Irán y Egipto según el reporte de Amnistía Internacional.

En dicho contexto, después de casi tres meses de confinamiento por la epidemia, el escenario económico de México exhibe una de las peores crisis económicas que se tengan registradas, al pronosticarse por especialistas e instituciones financieras una caída de al menos un 9,2\% en el crecimiento del producto interno bruto (PIB) en el año en curso, advirtiéndose una gran afectación empresarial en el país con el cierre de al menos diez mil empresas a finales del mes de mayo (Soto, 2020b), con incidencia negativa en los sectores del comercio, turismo, industria de la construcción, industria de la transformación, servicios para empresas y el hogar, transporte y comunicaciones, entre otros; mostrándose además con ello una disminución de más de un millón cien mil puestos de trabajos formales perdidos de febrero a junio del 2020 (IMSS).

\section{ACCIONES Y MEDIDAS PREVENTIVAS}

Es preciso señalar que desde que se presentó el primer caso de la covid-19 el 27 de febrero del 2020 (Suárez et al., 2020, p. 8), el Gobierno mexicano inició con una serie de acciones y medidas preventivas para contrarrestar o mitigar el virus también conocido como SARS-CoV2 con base en las recomendaciones emitidas por la Organización Mundial de la Salud (OMS), entre las que destacan: el aumento de las capacidades de monitoreo epidemiológico y análisis de laboratorio en búsqueda de casos sospechosos, vigilancia de viajeros extranjeros, capacitación a los profesionales de la salud, comunicación de riesgos a la población, intercambio sistemático y transparente con organizaciones internacionales, entre otras, ello con base en la información emitida por la Secretaría de Salud (SS).

Ante tal realidad, con fundamento en la Constitución Política de los Estados Unidos Mexicanos (CPEUM), ley suprema que instituye el derecho a la salud y a la obligatoriedad del Estado en garantizarla, así como lo estipulado por ordenamientos supranacionales en correspondencia a tal derecho humano y con base en la declaración emitida por la OMS al considerar a la epidemia como una emergencia de salud pública de interés internacional, el 24 de marzo del 2020 se emitieron algunas recomendaciones y medidas 
preventivas aplicables a los sectores privado, público y social, entre las que sobresalieron para el caso que nos concierne: prescindir de la asistencia a centros de trabajo de los adultos mayores a 65 años, la suspensión de actividades en dichos sectores que impliquen la concentración física, así como la continuidad de las operaciones de las empresas u organizaciones que resultaran necesarias para hacer frente a tal eventualidad, pero precisando además, el sostenimiento de las relaciones laborales conforme a los contratos individuales y colectivos con fundamento en la LFT y el artículo 123 de la CPEUM (SARS, 24 de marzo del 2020).

Inmediatamente, el 27 de marzo se pronunció un decreto de acciones extraordinarias, en el cual se instituye el requerimiento de la coordinación de las dependencias y entidades de la Administración Pública Federal (APF) para la creación de medidas de mitigación y control de la enfermedad originada por la covid-19 en las regiones afectadas de todo el territorio nacional, precepto publicado en el Diario Oficial de la Federación (DOF, 27 de marzo del 2020).

Posteriormente, el 30 de marzo se informó sobre el acuerdo por el que se declara como emergencia sanitaria, por causa de fuerza mayor, a la epidemia de enfermedad generada por el virus SARS-CoV2 (covid-19), manifestándose que derivada de la situación que guardó la pandemia en tal momento en el país, se dictaban diversas medidas por el Gobierno federal, de tal manera que el Consejo de Salubridad General en uso de su función establecida en el artículo 9..$^{\circ}$ fracción XVII de su Reglamento Interior determinó declarar como emergencia sanitaria por fuerza mayor a la epidemia de enfermedad generada por el virus SARS-Cov2, con el objeto de proteger la salud de los mexicanos (DOF, 30 de marzo del 2020).

Seguidamente, el 31 de marzo se publicó un acuerdo en el que se establecieron acciones extraordinarias para los sectores público, privado y social, entre las cuales resaltaron: la orden de suspensión inmediata de las actividades no esenciales durante el periodo del 30 de marzo al 30 de abril del 2020, con el objeto de mitigar la dispersión, evitar la carga de la enfermedad y la muerte ocasionada por el virus en mención en la comunidad, siendo las actividades prioritarias las requeridas para atender la emergencia sanitaria como las de la rama médica, paramédica, administrativa y de apoyo al Sistema Nacional de Salud. De igual manera, las actividades de los sectores primordiales de la economía, financieros, recaudación tributaria, venta de energéticos, gasolineras y gas, generación y distribución de agua potable, industria de alimentos y bebidas no alcohólicas, así como los mercados de alimentos, entre otras que se consideran fundamentales (DOF, 31 de marzo del 2020).

Después el 21 de abril, se emitió un nuevo acuerdo mediante el cual se modificó la fracción I del artículo primero del anterior acuerdo para ampliar el plazo de la suspensión de actividades no esenciales, quedando dicho periodo del 31 de marzo al 31 de mayo del año en curso, con la misma finalidad de la mitigación de la dispersión del virus (DOF, 21 de abril del 2020).

Como puede apreciarse en tales acciones y medidas por el Estado mexicano hasta el cierre del mes de mayo, conllevó la suspensión de las actividades no esenciales con 
el principal objetivo de evitar o bien disminuir la dispersión de la covid-19 y, por ende, sus efectos en la salud de la comunidad, tendiendo una incidencia inconcusamente no provocada en la relación laboral individual y colectiva de varios sectores económicos que cerraron sus puertas o bien interrumpieron su producción, tales como el turismo, el comercio, los servicios y la industria al no poder sostener económicamente dicho vínculo laboral; refiriendo en todo momento en dichas acciones y medidas a una emergencia sanitaria expresada el 30 de marzo por el Consejo de Salubridad General.

\section{SUSPENSIÓN DE LA RELACIÓN LABORAL}

El derecho laboral vislumbra una serie de principios y normas que reglamentan las relaciones entre el trabajador y el patrón y de ambas partes con el mismo Estado, teniendo su génesis para el caso que nos ocupa en el artículo 123 de la CPEUM, así como en la norma jurídica de aplicación estricta en todo el país e identificada como LFT (Sánchez, 2017, p. 1) y descrita con antelación.

De tal manera que dicha rama del derecho regula la actividad humana, donde se desprenden una serie de contextos con factores y afectaciones de la vida misma, con posibles incidencias en las relaciones laborales entre las partes que la conforman; sin embargo, con base en principios como la obligatoriedad, la protección, la seguridad y el derecho al trabajo entre otros, se debe orientar a proteger dicho vínculo en momentos difíciles o de contingencia, donde la figura de la suspensión laboral coadyuva a dichas situaciones conforme a la Ley en materia (Benrey, 2011, p. 281).

Al respecto, Pasco (1997, p. 481) dilucida de manera precisa que la naturaleza del contrato de trabajo es de tracto sucesivo al ejecutarse y prolongarse a través del tiempo con definida inspiración de subsistencia; mientras que la suspensión laboral concurre en búsqueda de proteger la continuidad de la relación contractual, evitando con ello la disolución definitiva cuando surge una causa suficiente y argumentada que imposibilita temporalmente su consecución, permitiendo así que el contrato sobrelleve una interrupción temporal sin perturbar su sustento fundamental, dispensando generalmente al trabajador y, en casos, al empleador del cumplimiento de sus obligaciones esenciales.

En esta misma tesitura y en primer término, en la LFT en su capítulo III e intitulado como "Suspensión de los efectos de las relaciones de trabajo", apartado que corresponde al título segundo denominado "Relaciones individuales de trabajo" de la norma en comento, en su artículo 42 instituye las causas de suspensión temporal de la relación laboral, escenario en el cual no existe la obligación del trabajador de prestar el servicio subordinado a pesar de la existencia de una remuneración económica de parte del patrón. Es preciso señalar que tal interrupción se efectúa sin responsabilidad tanto para el trabajador como para el patrón en atención a las causas que se instituyen en la norma jurídica, indicándose en su fracción primera el caso de la enfermedad contagiosa del trabajador.

En tal supuesto, en correspondencia al artículo 43 fracción I de la ley en cita, es obligación del trabajador informar oportunamente al empleador de su impedimento 
para presentarse a trabajar y, en su caso, proporcionarle el certificado de incapacidad temporal para el trabajo emitido por el IMSS. Dicha suspensión surtirá efectos a partir de la fecha en que el patrón tenga conocimiento de la enfermedad contagiosa hasta que termine el periodo estipulado por el instituto o antes si desaparece la incapacidad para el trabajo. De igual manera, es preciso señalar que el patrón tiene el derecho a contratar personal para la vacante en forma temporal o bien acudir a la rotación de su personal.

Para tal escenario, el artículo 96 de la Ley del Seguro Social (LSS) instituye que cuando el trabajador se encuentre asegurado ante el IMSS, este pagará un subsidio en dinero a partir del cuarto día del inicio de la incapacidad hasta por el término de 52 semanas, pudiéndose prorrogar hasta por 26 semanas adicionales en el caso de que el asegurado permanezca incapacitado para regresar a sus labores, previo dictamen emitido por el mismo instituto. Una vez dado de alta, el trabajador deberá regresar a su trabajo al día siguiente de la terminación de la causa de la suspensión, con fundamento en lo estipulado en el artículo 45 fracción I de la LFT.

Ahora bien, en el capítulo VII de la LFT, el apartado que refiere a la "Suspensión colectiva de las relaciones de trabajo", en su numeral 427 establece entre uno de sus motivos de suspensión temporal de las relaciones de trabajo de una empresa o establecimiento, lo estipulado en la fracción VII y que a la letra señala: "la suspensión de labores o trabajos, que declare la autoridad sanitaria competente, en los casos de contingencia sanitaria".

Es preciso señalar que la génesis de la fracción del numeral antes indicado, su aditamento al artículo 427 de la LFT, obedeció a la experiencia de la pandemia de gripe A (H1N1) también conocida como influenza y que surgió en el 2009 con el objeto de considerar sucesos análogos de salud pública que pudieran perturbar el desempeño regular de las relaciones de trabajo, mediante una declaratoria de suspensión de labores dictada por la autoridad sanitaria (DOF, 30 noviembre 2012).

Asimismo, en lo referente a lo instituido en la fracción VII del artículo 427, es decir, en caso de que la Secretaría de Salud al dictaminar declaratoria de suspensión de labores correspondiente al avance de la covid-19, las relaciones entre patrones y empleados deben de ser suspendidas, absteniéndose a presentarse a laborar durante tal declaratoria; sin la necesidad de requerirse la aprobación del Tribunal, obligándose el empleador a pagar a sus trabajadores el equivalente a un día de salario mínimo general vigente $(\$ 185,56$ aplicable para los municipios que se encuentran en la franja fronteriza del norte del país y $\$ 123,22$ para el resto del país) ${ }^{2}$, por cada día que dure la suspensión, sin que pueda exceder de un mes, todo ello con fundamento en el artículo 429 fracción VII de la misma norma en cita.

Como es de advertirse, los acuerdos y decretos emitidos por el Gobierno federal y la declaratoria del Consejo de Salubridad General descritos con anterioridad,

2 Salarios mínimos que rigen al país y vigentes a partir del 1. ${ }^{\circ}$ de enero del 2020. Resolución publicada en el DOF del 23 de diciembre del 2019. 
formalizaron los esfuerzos en materia del combate a la covid-19, facultando con ello a diversas instituciones públicas y a la misma sociedad para la ejecución de dichas acciones y medidas preventivas; reflejándose con ello, un reconocimiento implícito del problema que representó y que sigue reflejándose en la actualidad la enfermedad citada. Entre tales acciones, se instituyó el cierre de espacios públicos, la suspensión de actividades no esenciales y el confinamiento domiciliario voluntario, estas son gestiones de prevención perseverantes con las mejores prácticas a nivel internacional y que indudablemente han premiado con el salvamento de vidas de las mexicanas y mexicanos. No obstante, su ejecución en muchos de los ámbitos sociales y económicos, y para el caso que nos incumbe, en el campo del derecho laboral no se estuvo libre de interpretaciones y aplicaciones controversiales.

Toda vez que con fundamento en lo instituido en el artículo 356 de la Ley General de Salud (LGS) y numeral que conforma al título décimo quinto e intitulado "Sanidad internacional", se emite de parte del Consejo de Salubridad General una declaratoria el día 30 de marzo, empleando el término emergencia sanitaria en su apreciación de la pandemia como un problema de salud y con carácter fundamental. Se presume, que dicha dependencia gubernamental recurrió a tal expresión como la definición legal más aproximada a los propósitos del acuerdo por la ausencia de una categorización concreta en la normatividad aplicable.

Dicha locución manifestada recayó de manera controversial en la aplicación y legal ejecución de la LFT, en virtud de que en la misma norma jurídica existe dicha expresión en una sola ocasión y que se localiza en su artículo 132 fracción XIX bis, el cual se refiere a la obligación de los patrones del cumplimiento de las disposiciones que fije la autoridad competente en caso de "emergencia sanitaria"; sobresaliendo en el resto de las disposiciones de la ley referentes a una declaratoria sanitaria, pero con el empleo del término contingencia sanitaria, verbigracia, los numerales ya antes descritos en el presente estudio.

Por tal motivo, la discordancia de los términos emergencia sanitaria y contingencia sanitaria, desde un estricto sentido jurídico, dificulta su aplicación, pues la LFT distingue a una contingencia con suspensión de labores, mediante la cual los empleadores detienen su actividad empresarial con la obligación de pagar únicamente una indemnización de un salario mínimo hasta por un mes de sus subordinados suspendidos por contingencia sanitaria. Asimismo, se aprecia que otro aspecto controversial lo simboliza que en los acuerdos de emergencia sanitaria se manifestó por parte del gobierno, la "suspensión de actividades", mas no la "suspensión de labores" como lo indica la norma laboral mexicana (Caro, 2020, citado por Soto, 2020a).

De igual manera, es preciso indicar que se carece de la exégesis de los términos antes aludidos en los ordenamientos jurídicos de donde surge su aplicación como instrumentos de políticas públicas en materia de salud en general con derivaciones legales directas en el ámbito laboral (García, 2020), generándose así la controversia en estudio en el ejercicio de la legislación. 
En atención al Diccionario de la Real Academia Española (DRAE), el término emergencia significa "situación de peligro o desastre que requiere una acción inmediata", mientras que el vocablo contingencia se define como "posibilidad de que algo suceda o no suceda" o bien "cosa que puede suceder o no suceder", por lo que con tal diferenciación de dichas expresiones, se estima la imperiosa necesidad de reformar lo relativo a la LFT, donde los textos que refieran a contingencia sanitaria sean modificados por emergencia sanitaria por la amplitud de su interpretación, lo cual armoniza con la ya propuesta iniciativa de reforma a la norma laboral mexicana realizada por la diputada Martha Angélica Zamudio Macías del Grupo Parlamentario del Movimiento Ciudadano (Zamudio, 2020).

\section{CONCLUSIONES}

Indiscutiblemente, la pandemia ocasionada por el virus SARS-Cov2 (covid-19) ha sido el desafío más relevante que ha desconcertado a la humanidad en el siglo en curso, poniendo a prueba a organismos internacionales, gobiernos e instituciones en el combate de este, en virtud de que sus efectos económicos y de salud cobran el centro de atención a nivel mundial y evidenciándonos que no estábamos preparados para algo de esta magnitud.

Precisamente en el caso de controversia expuesto, desde el punto de vista en la aplicación y ejecución del derecho, es de apreciarse la falta de congruencia de la normatividad exhibida, en vista de que en los numerales de la LGS que refieren a la situación de emergencia, tales como los artículos 157 Bis 11, 181, 182, 356 y 408 fracción $\mathrm{V}$, no precisan su acepción. Asimismo, solamente el artículo 356 alude a la expresión "emergencia sanitaria" sin proporcionar un significado al respecto; careciendo dicha norma jurídica del enunciado "contingencia sanitaria".

Mientras que en la LFT, el vocablo de emergencia se encuentra en cuatro de sus numerales, tales como los artículos 132 fracción XIX Bis, 237 fracción IX, 262 fracción IV y 263 fracción III, donde únicamente el primero hace alusión a la expresión "emergencia sanitaria" y los restantes se refieren a la emergencia aplicable a otras áreas. De igual manera, en los artículos 42 Bis, 132 fracción XIX Bis, 168, 175, 427 fracción VII, 432 y 512-D Ter, de la norma en cita se señala la expresión "contingencia sanitaria".

Sobre la base de las consideraciones anteriores, al carecerse en los ordenamientos jurídicos antes citados de una definición de "emergencia sanitaria" y "contingencia sanitaria", ello lleva a tener que realizar una interpretación en su sentido amplio, pues en primer lugar en la LGS se estipula que como parte de las funciones de la autoridad sanitaria es el de emitir la declaratoria de "emergencia sanitaria", mientras que en la aplicación de la LFT para efectos de la suspensión laboral se requiere de la emisión de tal expresión como "contingencia sanitaria" de parte de dicha autoridad, lo que hace indispensable ya sea de la reforma de la LGS y de la LFT en tales supuestos para evitar la incompatibilidad y controversia que actualmente se ha suscitado en lo futuro e 
impidiendo con ello, la confrontación entre patrones y trabajadores en un mal momento como el que aún impera en México.

\section{REFERENCIAS}

Amnistía Internacional. Mapeo de las muertes de trabajadores de salud por covid-19. https://www.amnesty.org/en/latest/news/2020/09/mapping-covid19-health-worker-deaths/ [Consultado el 3 de septiembre del 2020].

Benrey, J. (2011). Análisis de la figura de la suspensión de contrato de trabajo del trabajador particular en Colombia y algunas menciones a la legislación extranjera. Revista Estudios Socio-Jurídicos, 13, 379-410.

CEPAL (2020). América Latina y el Caribe ante la pandemia del covid-19. Efectos económicos y Sociales. Informe especial COVID-19 n. ${ }^{\circ}$ 1. https://repositorio.cepal.org/bitstream/handle/11362/45337/ S2000264_es.pdf? sequence=6\&isAllowed =y [Extraído el 25 de agosto 2020].

Constitución Política de los Estados Unidos Mexicanos. Constitución publicada en el Diario Oficial de la Federación el 5 de febrero de 1917. Última reforma publicada en el Diario Oficial de la Federación el 8 de mayo del 2020. http://www.diputados.gob.mx/ LeyesBiblio/pdf/1_080520.pdf.

Covid-19 Tablero México. Covid-19 México. https:/coronavirus.gob.mx/datos/

DOF (2012). Decreto por el que se reforman, adicionan y derogan diversas disposiciones de la Ley Federal del Trabajo. http://www.diputados.gob.mx/sedia/biblio/prog_leg/005_ DOF_30nov12.pdf.

DOF (2020). Acuerdo por el que se declara como emergencia sanitaria por causa de fuerza mayor, a la epidemia de enfermedad generada por el virus SARS-CoV2 (COVID-19). https:// www.dof.gob.mx/nota_detalle.php?codigo $=5590745$ \&fecha $=30 / 03 / 2020$

DOF (2020). Acuerdo por el que se establecen acciones extraordinarias para atender la emergencia sanitaria generada por el virus SARS-CoV2. https://www.dof.gob.mx/nota_detalle. php? codigo $=5590914 \&$ fecha $=31 / 03 / 2020$

DOF (2020). Acuerdo por el que se establecen las medidas preventivas que se deberán implementar para la mitigación y control de los riesgos para la salud que implica la enfermedad por el virus sars-CoV2 (covid-19). https://www.dof.gob.mx/nota_detalle.php?codigo= 5590339\&fecha $=24 / 03 / 2020$

DOF (2020). Acuerdo por el que se modifica el similar por el que se establecen acciones extraordinarias para atender la emergencia sanitaria generada por el virus SARS-CoV2, publicado el 31 de marzo de 2020. https://www.dof.gob.mx/nota_detalle.php?codigo= $5592067 \&$ fecha $=21 / 04 / 2020$

DOF (2020). Decreto por el que se declaran acciones extraordinarias en las regiones afectadas de todo el territorio nacional en materia de salubridad general para combatir la enfermedad grave de atención prioritaria generada por el virus SARS-CoV2 (COVID-19). https://www. dof.gob.mx/nota_detalle.php?codigo $=5590673$ \&fecha $=27 / 03 / 2020$

DOF. (2019). Resolución del H. Consejo de Representantes de la Comisión Nacional de los Salarios Mínimos que fija los salarios mínimos general y profesionales que habrán de 
regir a partir del 1 de enero de 2020. https://www.dof.gob.mx/nota_detalle.php?codig $\mathrm{o}=5582641 \& \mathrm{fecha}=23 / 12 / 2019$

García, L. (2020). ¿Contingencia o emergencia sanitaria? https://forojuridico.mx/contingencia-oemergencia-sanitaria/

IMSS. Mapa en tiempo real de casos de coronavirus por Jobns Hopkins School. http://cvoed.imss.gob.mx/ mapa_coronavirus/

IMSS. Mapa interactivo, series de tiempo, puestos de trabajo. https://public.tableau.com/profile/imss. cpe\#!/vizhome/Histrico_4/Empleo_h?publish=yes

Ley Federal del Trabajo. Nueva Ley publicada en el Diario Oficial de la Federación el 1. ${ }^{\circ}$ de abril de 1970. Última reforma publicada en el Diario Oficial de la Federación el 2 de julio del 2019. http://www.diputados.gob.mx/LeyesBiblio/pdf/125_020719.pdf.

Ley General de Salud. Nueva Ley publicada en el Diario Oficial de la Federación el 7 de febrero de 198. Última reforma publicada en el Diario Oficial de la Federación el 24 de enero del 2020. http://www.diputados.gob.mx/LeyesBiblio/pdf/142_240120.pdf.

OPS. La Región de las Américas reporta la mayoría de las nuevas muertes por covid-19 en todo el mundo. https://www.paho.org/es/noticias/1-9-2020-region-americas-reporta-mayoria-nuevasmuertes-por-covid-19-todo-mundo

Pasco, M. (1997). Suspensión del contrato de trabajo. En N. Buen Lozano y E. Morgado Valenzuela (coords.), Instituciones del derecho del trabajo y de la seguridad social (pp. 481-499). Instituto de Investigaciones Jurídicas. Serie G: Estudios Doctrinales.

Sánchez, A. (2017). Derechos de los trabajadores. 1. ${ }^{a}$ edición. Instituto de Investigaciones Jurídicas. Ciudad de México: Universidad Nacional Autónoma de México.

Secretaría de Salud. 076. covid-19: Acciones de preparación y respuesta en México. https://www.gob. $\mathrm{mx} /$ salud/prensa/076-covid-19-acciones-de-preparacion-y-respuesta-en-mexico

Soto, G. (2020a). México, entre la contingencia y la emergencia laboral por el covid-19. https://lexlatin. com/reportajes/mexico-contingencia-emergencia-laboral-covid-19

Soto, G. (2020b). La otra tragedia: 10 mil empresas y negocios desaparecen por covid-19. https://www. elfinanciero.com.mx/bloomberg-businessweek/la-pandemia-vino-a-devorarlas-10-milempresas-y-negocios-ya-no-estan

Suárez, V. et al. (2020). Epidemiology of covid-19 in Mexico: From the 27th of February to the 30 th of April 2020. Revista Clínica Española, mayo 2020. https://doi.org/10.1016/j.rce.2020.05.007

Zamudio, M. (2020). Iniciativa con Proyecto de Decreto por el que se reforma el Artículo 42 Bis, la Fracción XIX Bis en el Artículo 132, los Artículos 168 y 175, la Fracción VII en el Artículo 427 y los Artículos 432 y 512-D Ter de la Ley Federal del Trabajo en materia de atención y empleo durante emergencias sanitarias. https://infosen.senado.gob.mx/sgsp/ gaceta/64/2/2020-05-20-1/assets/documentos/Inic_MC_Dip_Martha_Zamudio_art_ 42bis_132_168_175__427_432_512d_LFT.pdf. 